\title{
Cytogenetic Characterisation of Nattukuttai - A Non-descript Cattle Population of Tamil Nadu
}

\author{
Ymberzal Koul, V. Harshini, S.M.K. Karthickeyan, K. Thilak Pon Jawahar, A. Gopinathan
}

10.18805/ag.D-5056

\begin{abstract}
Background: Nattukuttai is a small-sized cattle population, native to north-eastern districts of Tamil Nadu. In light of the ongoing research on genetic characterisation of cattle genetic resources of India, the present study was undertaken with the objective of cytogenetic characterisation of Nattukuttai cattle, which is imperative for its conservation and genetic implications to breeding programs.

Methods: Blood samples from ten Nattukuttai cattle (five males and five females) were utilized to study the chromosome profile through short-term lymphocyte culture method. Good metaphase spreads were selected for estimation of the relative length, arm ratio, centromeric index and morphological index.

Result: The diploid number was 60 . All the 29 pairs of autosomes and Y-chromosome were acrocentric while X-chromosome was sub-metacentric. The mean relative length of autosomes ranged from $5.24 \pm 0.08$ to $1.90 \pm 0.06$. X-chromosome was the largest in the karyotype $(5.64 \pm 0.12)$, while the $Y$-chromosome was the smallest $(1.85 \pm 0.03)$. The arm ratio, centromeric index and morphological index were $1.98 \pm 0.02,0.33 \pm 0.03$ and $4.06 \pm 0.4$ respectively. The study revealed that the chromosome architecture of Nattukuttai cattle was similar to that of other breeds of Zebu cattle.
\end{abstract}

Key words: Cattle, Characterisation, Cytogenetic, Karyotype, Nattukuttai.

\section{INTRODUCTION}

Nattukuttai cattle, locally known as Nattu Madu, is a nondescript cattle genetic group of Tamil Nadu. It plays a major role in socio-economic status of people in its breeding tract, which comprises Kancheepuram, Villupuram and Tiruvallur districts of north-east agroclimatic zone of Tamil Nadu (Vinothkumar, 2014). Nattukuttai cattle are short and compact with brown or grey body colour. Male cattle are procured for draught purpose; while the cows for milk production, yielding around three litres of milk per day. Marginal farmers, women and labourers keep this cattle group as they are easy to manage and cost of maintenance is less as compared to Jersey crossbred cattle (Vivekanandan and Alagumalai, 2013). Nattukuttai cattle are also superior in heat tolerance than Jersey crossbred cattle, as indicated by various heat tolerance indices (Vinothkumar, 2014). Despite possessing beneficial characteristics, such as heat and disease tolerance, nondescript cattle of India are at an increased risk of genetic degradation caused by introduction of exotic germplasm. Hence, to safeguard animal genetic resources, Food and Agriculture Organisation (FAO) proposed a global programme of phenotypic and molecular characterisation of available animal germplasm. Conservation of existing livestock resources is prerequisite to formulation of future breeding strategies.

Characterisation of animal genetic resources at phenotypic level involves identification of distinct breed populations, description of their typical physical and production characteristic and documentation of any unique features in terms of adaptation and production (FAO, 2012).
Department of Animal Genetics and Breeding, Madras Veterinary College, Chennai-600 007, Tamil Nadu, India.

Corresponding Author: Ymberzal Koul, Department of Animal Genetics and Breeding, Madras Veterinary College, Chennai-600 007, Tamil Nadu, India. Email: ymberzal@gmail.com

How to cite this article: Koul, Y., Harshini, V., Karthickeyan, S.M.K., Jawahar, K.T.P. and Gopinathan, A. (2022). Cytogenetic Characterisation of Nattukuttai-A Non-descript Cattle Population of Tamil Nadu. Agricultural Science Digest. 42(1): 109-113. DOI: 10.18805/ag.D-5056.

Submitted: 14-10-2019 Accepted: 11-08-2020 Online: 13-08-2021

Molecular genetic characterisation, commonly undertaken using microsatellite markers, explores genetic variation between and within animal populations and facilitates in determination of evolutionary relationship among animal populations. FAO and International Society of Animal Genetics-FAO Advisory Group on Animal Genetic Diversity proposed panels of thirty microsatellite markers for cattle (FAO, 2011) and recommended the usage of all thirty microsatellites for genetic diversity analysis. Apart from phenotypic and molecular studies, cytogenetic studies are also incredibly useful in genetic characterisation and effective conservation of any species (Benirschke and Kumamoto, 1991).

Karyological methods are useful in differentiating cattle of exotic origin (Bos taurus) from indigenous cattle (Bos indicus) based on Y-chromosome polymorphism. Y-chromosomes of Bos indicus and breeds derived from Bos indicus bulls are acrocentric while those of Bos taurus, Sanga and 
breeds derived from these bulls are metacentric or submetacentric (Potter and Upton, 1979). The morphological difference between Bos taurus and Bos indicus $\mathrm{Y}$-chromosome is the consequence of pericentric inversion (Pinheiro et al., 1980). Hence, karyotyping can be employed to take culling decisions at farms where crossbred animals are required to have an exotic sire line. Karyotyping is also used in detecting numerical and structural abnormalities, chromosomal damage or irregularity in cell cycle which indicate toxicity and carcinogenic activity (Wójcik and Szostek, 2019). However, there are certain limitations towards the use of conventional karyotyping because it requires the culture of living cells and hence many factors may lead to failure in obtaining results, e.g. delay in transport of blood sample, exposure to extreme temperature, bacterial contamination, low lymphocyte count within the sample and low resolution limit. Despite these limitations, conventional banded karyotyping is recognized as the gold standard for detection of chromosomal abnormalities. Chromosomal studies are available for lesser number of breeds; hence the present study was undertaken to characterise Nattukuttai genetic group by cytogenetic norms with focus on chromosome morphometrics and cytogenetic screening.

\section{MATERIALS AND METHODS}

Ten blood samples (five male and five females) were collected from breeding tract of Nattukuttai (Kancheepuram, Villupuram and Tiruvallur districts). Five $\mathrm{ml}$ blood per animal was drawn aseptically from jugular vein into a sterile vacutainer tube containing $40 \mathrm{IU}$ of sodium heparin. Culture was set up at cytogenetics laboratory of Department of Animal Genetics and Breeding, Madras Veterinary College, as per the short-term lymphocyte culture method of Moorehead et al. (1960) with slight modifications by adding $7 \mathrm{ml}$ of the complete medium (M/s. Euroclone, Italy; containing culture medium and mitogen), 0.2 to $0.3 \mathrm{ml}$ of buffy coat and 2 to 3 drops of whole blood into each centrifuge tube. The labelled centrifuge tubes were sealed with parafilm and incubated at $37^{\circ} \mathrm{C}$ at five per cent $\mathrm{CO}_{2}$ concentration for 72 hours. Exactly one and a half hour (i.e. at $70.5 \mathrm{hr}$ ) prior to harvesting the cells, the centrifuge tubes were taken out of the incubator and $80 \mu \mathrm{l}$ of colchicine was added to each culture tube. At the end of 72 hours, the culture vials were centrifuged at $1500 \mathrm{rpm}$ for ten minutes after which the supernatant fluid was discarded, leaving a little amount of medium above the cell button. Seven $\mathrm{ml}$ of hypotonic solution $(0.075 \mathrm{M} \mathrm{KCl})$ was added to cell pellet of each tube, kept at $37^{\circ} \mathrm{C}$ for 30 minutes and centrifuged at $1000 \mathrm{rpm}$ for 10 minutes. The supernatant was discarded, and cells were re-suspended with $8 \mathrm{ml}$ of freshly prepared pre-chilled Carnoy's fluid. Tubes were again centrifuged at $1500 \mathrm{rpm}$ for 10 minutes, supernatant discarded, and washings were repeated until a clear white pellet was obtained. About $20 \mu \mathrm{l}$ of cell suspension was dropped on grease free slides with an angle of $45^{\circ}$ and height of 2 to 3 feet from the ground, stained with 4 per cent Giemsa for 20 minutes, air dried and checked for metaphase spreads.

Slides containing good quality metaphase spreads were selected from further processing. Vernier caliper (Mitutoyo, Japan) was used for measuring the length of short arm ( $p)$, long arm (q) and total length of chromosomes. Arm ratio, centromeric index and morphological index were estimated. The relative lengths of each chromosome were measured as the percentage of it to the total haploid genome length (excluding Y-chromosome).

\section{RESULTS AND DISCUSSION}

The karyotypes of male and female Nattukuttai cattle are presented in Fig 1. The diploid chromosome number was found to be 60 , which is in agreement with earlier reports by Girija (1994) in Vechur, Balaji et al. (2006) in Deoni, Kumarasamy et al. (2008) in Umblachery, Suresh et al. (2015) in Malnad Gidda, Bharathi et al. (2015) in Punganur, Choudhury et al. (2014) and Longkumer et al. (2015) in ThoTho cattle of north-eastern states of India and Bharti et al. (2017) in Ongole breed. There were 29 pairs of autosomes

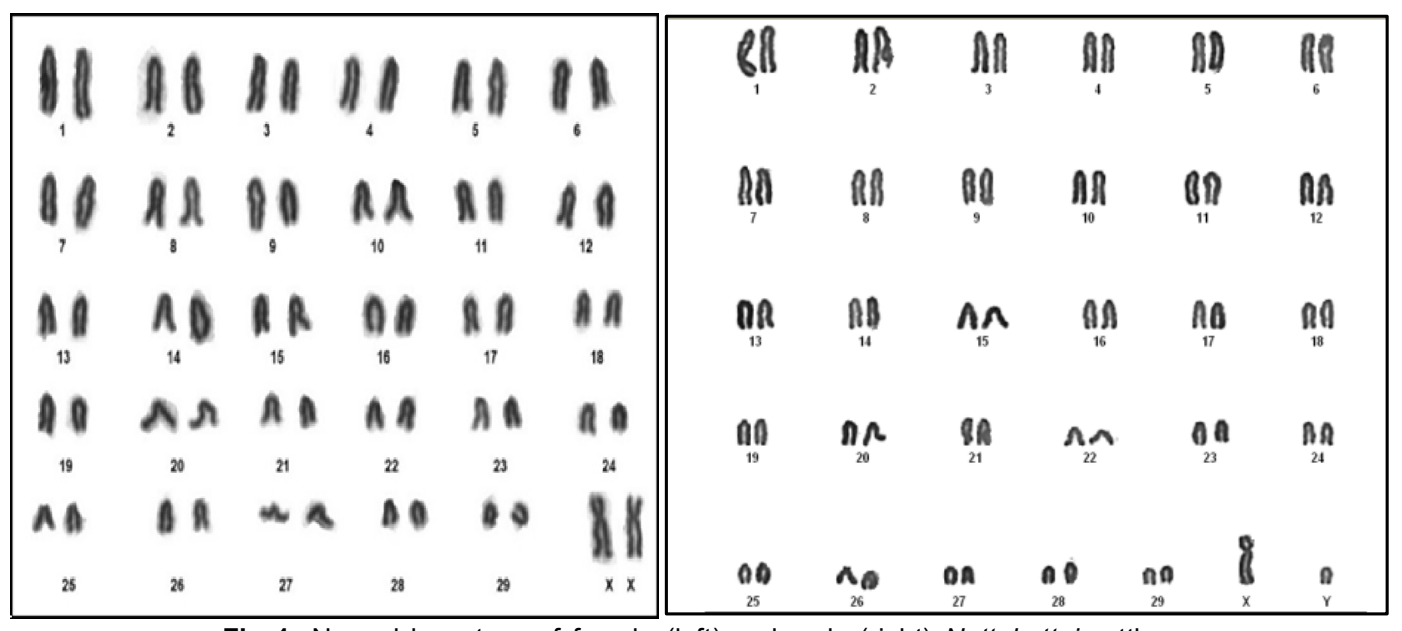

Fig 1: Normal karyotype of female (left) and male (right) Nattukuttai cattle. 
Table 1: Relative lengths (per cent) of chromosomes in Nattukuttai cattle.

\begin{tabular}{|c|c|c|c|}
\hline \multirow[b]{2}{*}{ Chromosome number } & \multicolumn{3}{|c|}{ Relative length (per cent) } \\
\hline & $\begin{array}{c}\text { Male } \\
\text { (Mean } \pm S . E)\end{array}$ & $\begin{array}{c}\text { Female } \\
(\text { Mean } \pm \text { SE })\end{array}$ & $\begin{array}{c}\text { Overall } \\
(\text { Mean } \pm \text { SE })\end{array}$ \\
\hline 1 & $5.16 \pm 0.09$ & $5.32 \pm 0.07$ & $5.24 \pm 0.08$ \\
\hline 2 & $4.92 \pm 0.07$ & $4.73 \pm 0.05$ & $4.825 \pm 0.06$ \\
\hline 3 & $4.65 \pm 0.07$ & $4.45 \pm 0.07$ & $4.55 \pm 0.07$ \\
\hline 4 & $4.53 \pm 0.05$ & $4.32 \pm 0.07$ & $4.425 \pm 0.06$ \\
\hline 5 & $4.41 \pm 0.05$ & $4.12 \pm 0.05$ & $4.265 \pm 0.05$ \\
\hline 6 & $4.11 \pm 0.02$ & $4.04 \pm 0.04$ & $4.075 \pm 0.03$ \\
\hline 7 & $3.97 \pm 0.03$ & $3.99 \pm 0.01$ & $3.98 \pm 0.02$ \\
\hline 8 & $3.92 \pm 0.01$ & $3.87 \pm 0.03$ & $3.895 \pm 0.02$ \\
\hline 9 & $3.83 \pm 0.01$ & $3.72 \pm 0.03$ & $3.775 \pm 0.02$ \\
\hline 10 & $3.71 \pm 0.02$ & $3.61 \pm 0.02$ & $3.66 \pm 0.02$ \\
\hline 11 & $3.55 \pm 0.03$ & $3.53 \pm 0.01$ & $3.54 \pm 0.02$ \\
\hline 12 & $3.28 \pm 0.02$ & $3.47 \pm 0.02$ & $3.375 \pm 0.02$ \\
\hline 13 & $3.21 \pm 0.02$ & $3.34 \pm 0.02$ & $3.275 \pm 0.02$ \\
\hline 14 & $3.04 \pm 0.01$ & $3.23 \pm 0.03$ & $3.135 \pm 0.02$ \\
\hline 15 & $2.98 \pm 0.02$ & $3.14 \pm 0.02$ & $3.06 \pm 0.02$ \\
\hline 16 & $2.87 \pm 0.04$ & $3.09 \pm 0.02$ & $2.98 \pm 0.03$ \\
\hline 17 & $2.75 \pm 0.03$ & $2.97 \pm 0.03$ & $2.86 \pm 0.03$ \\
\hline 18 & $2.72 \pm 0.01$ & $2.86 \pm 0.03$ & $2.79 \pm 0.02$ \\
\hline 19 & $2.68 \pm 0.02$ & $2.77 \pm 0.02$ & $2.725 \pm 0.02$ \\
\hline 20 & $2.59 \pm 0.02$ & $2.7 \pm 0.02$ & $2.645 \pm 0.02$ \\
\hline 21 & $2.52 \pm 0.03$ & $2.59 \pm 0.01$ & $2.555 \pm 0.02$ \\
\hline 22 & $2.46 \pm 0.01$ & $2.53 \pm 0.03$ & $2.495 \pm 0.02$ \\
\hline 23 & $2.33 \pm 0.02$ & $2.36 \pm 0.02$ & $2.345 \pm 0.02$ \\
\hline 24 & $2.24 \pm 0.02$ & $2.29 \pm 0.02$ & $2.265 \pm 0.02$ \\
\hline 25 & $2.17 \pm 0.03$ & $2.23 \pm 0.03$ & $2.2 \pm 0.03$ \\
\hline 26 & $2.08 \pm 0.04$ & $2.18 \pm 0.02$ & $2.13 \pm 0.03$ \\
\hline 27 & $1.98 \pm 0.02$ & $2.07 \pm 0.02$ & $2.025 \pm 0.02$ \\
\hline 28 & $1.92 \pm 0.03$ & $1.98 \pm 0.05$ & $1.95 \pm 0.04$ \\
\hline 29 & $1.86 \pm 0.07$ & $1.94 \pm 0.05$ & $1.90 \pm 0.06$ \\
\hline$x$ & $5.55 \pm 0.08$ & $5.74 \pm 0.15$ & $5.645 \pm 0.12$ \\
\hline Y & $1.85 \pm 0.03$ & - & $1.85 \pm 0.03$ \\
\hline
\end{tabular}

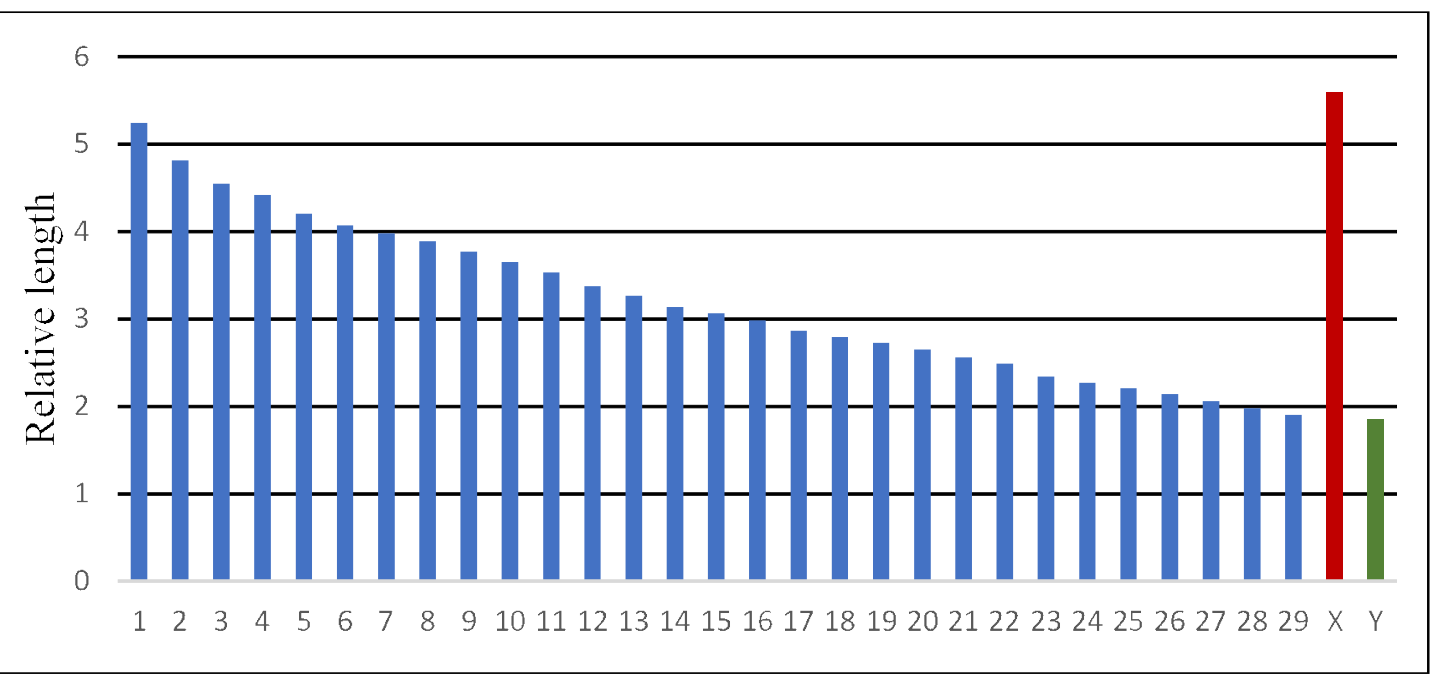

Fig 2: Idiogram of Nattukuttai cattle. 
Cytogenetic Characterisation of Nattukuttai - A Non-descript Cattle Population of Tamil Nadu

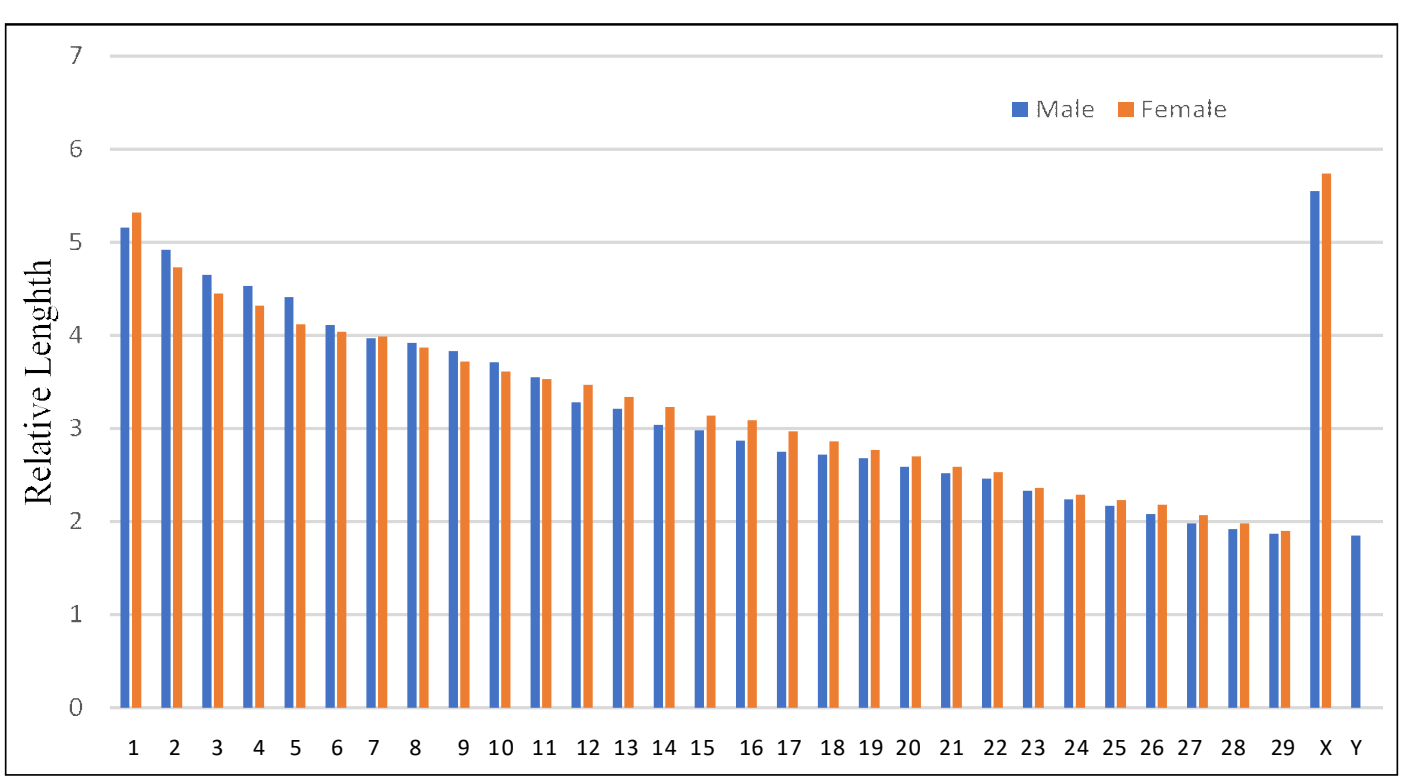

Fig 3: Comparative idiogram for chromosomes of male and female Nattukuttai cattle.

and one pair of allosome. All the 29 pairs of autosomes were acrocentric and X-chromosome was submetacentric. Ychromosome was the smallest acrocentric in all the metaphase spreads, thus confirming paternal descent through Bos indicus. The largest chromosome in the genome was X-chromosome, unlike that of Punganur and Tho-Tho cattle where the first chromosome was the largest (Bharathi et al., 2015; Longkumer et al., 2015).

The relative length of chromosomes descends uniformly as can be seen in the idiogram (Fig 2 and Fig 3). The mean relative length of autosomes for combined population varied from 5.24 to 1.90 per cent (Table 1) which is in accordance with the estimates reported by Girija (1994) in Vechur (5.431 to 1.757), Kumarasamy et al. (2008) in Umblachery (4.637 to 1.850 ), Bharathi et al. (2015) in Punganur (5.34 to 1.69), Longkumer et al. (2015) in Tho-Tho cattle (5.31 to 1.86), and Bharti et al. (2017) in Ongole breed (5.24 to 1.92). The $X$-chromosome contributed 5.64 per cent to the total genome which is higher than 5.002 per cent as observed in Umblachery (Kumarasamy et al., 2008) and 4.81 per cent as observed in Punganur (Bharathi et al., 2015); but in agreement with estimates of 5.591 in Vechur (Girija, 1994), 5.53 in Tho-Tho cattle (Longkumer et al., 2015) and 5.42 in Ongole (Bharti et al., 2017). The Y-chromosome had a relative length of 1.68 per cent, which is comparable to the previous reports, except Vechur, where the relative length was reported as 2.875 by Girija (1994).

The mean arm ratio, centromeric index and morphological index were $1.98,0.33$ and 4.06 respectively. The arm ratio value of $\mathrm{X}$-chromosome in the present study is similar to values reported for Vechur (2.182), Malnad Gidda (2.12) Umblachery (2.035) and Ongole (1.87); but higher to value reported in Punganur (1.55) by previously mentioned researchers. Arm ratio of more than 1.00 also confirmed the submetacentric nature of $\mathrm{X}$-chromosome. The value for centromeric index in Nattukuttai cattle is in agreement with values reported in the mentioned breeds. The morphological index, however, is lower in Nattukuttai chromosomes as compared to Punganur (5.12) and Ongole (5.25).

\section{CONCLUSION}

The modal chromosome number in Nattukuttai cattle was 60, which constituted 29 pairs of acrocentric autosomes and submetacentric X-chromosome. Y-chromosome was acrocentric. Various morphometric measurements suggested that the chromosome architecture of Nattukuttai cattle was similar to that of recognized breeds of Bos indicus from various parts of India. The findings from present study form basis for further cytogenetic investigation and screening of breeding bulls for detection of chromosomal abnormalities.

\section{REFERENCES}

Balaji, R., Gupta, B.R., Rao, G.N. and Reddy, G.V. (2006). Cytogenetic characterization of Deoni cattle. Indian Journal of Animal Research. 40(1): 20-24.

Benirschke, K. and Kumamoto, A.T. (1991). Mammalian cytogenetics and conservation of species. Journal of Heredity. 82(3): 187-191.

Bharathi, G., Sakaram, D., Prakash M.G. and Gupta, B.R. (2015). Cytogenetic characterization of Punganur cattle. International Journal of Science and Applied Research. 2(10): 46-52.

Bharti, A., Reddy P.R., Prakash M.G. and Sakaram, D. (2017). Cytogenetic characterization of Ongole cattle. International Journal of Advanced Biological and Biomedical Research. 7(3): 574-577.

Choudhury, H., Sarmah, V.B., Dhali, A., Choudhury, M.D., Vidyarthi, V.K., Kumar S., Baruah, U.K and Sarma, D.K. (2014). Chromosomal characteristics of Tho-Tho cattle (Bos indicus) in Nagaland, India. African Journal of Agricultural Research. 9(38): 2894-2900. 
FAO. (2011). Molecular Genetic Characterization of Animal Genetic Resources. FAO Animal Production and Health Guidelines. No. 9. Rome.

FAO. (2012). Phenotypic characterization of animal genetic resources. FAO Animal Production and Health Guidelines No. 11. Rome.

Girija, C.R., (1994). Characterization and evaluation of the dwarf cattle of Kerala. Ph.D. thesis submitted to Kerala Agriculture University.

Kumarasamy, P., Sivaselvam, S.N., Rajendran, R., Thangaraju, P. and Nainar, A.M. (2008). Chromosomal characterization of Umblachery breed of cattle (Bos indicus)- A famous South Indian breed of Tamil Nadu, India. Indian Journal of Science and Technology. 1(6): 1-3.

Longkumer, I., Mukherjee, A., Yenisetti, S.C., Mukherjee, S. and Mech, M. (2015). Complete cytogenetic insight of ThoTho cattle. Journal of Agricultural Science and Technology. 5: 277-285.

Moorhead, P.S., Nowell, P.C., Mellman, W.J., Battips, D.T. and Hungerford, D.A. (1960). Chromosome preparations of leukocytes cultured from human peripheral blood. Experimental Cell Research. 20(3): 613-616.
Pinheiro, L.E.L., Moraes, J.C.F., Mattevi, M.S., Erdtmann, B., Salzano, F.M. and Filho, A. M. (1980). Two types of $Y$ chromosome in a Brazilian cattle breed. Caryologia. 33(1): 25-32.

Potter, W.L. and Upton, P.C. (1979). Y chromosome morphology of cattle. Australian Veterinary Journal. 55(11): 539-541.

Suresh, S.C., Nagaraja, C.S. and Satheesha, G.M. (2015). Cytogenetic studies in Malnad Gidda cattle. Wayamba Journal of Animal Science. Article. (1424965516): 1059-1065.

Vinothkumar, D. (2014). Evaluation of performance characteristics of a distinct cattle population (Nattukuttai madu) in northeastern agro climatic zone of Tamil Nadu. M.V.Sc. Thesis submitted to the Tamil Nadu Veterinary and Animal Sciences University, Chennai-51.

Vivekanandan, P. and Alagumalai, (2013). Community Conservation of Local Livestock Breeds. NABARD Supported Project Report towards Capacity Building of Livestock Keepers for Conserving 10 Local Breeds in Tamil Nadu. Published by Sustainable-Agriculture and Environmental Voluntary Action (SEVA) 2013.

Wójcik, E. and Szostek, M. (2019). Assessment of genome stability in various breeds of cattle. PloS one. 14(6): e0217799. 